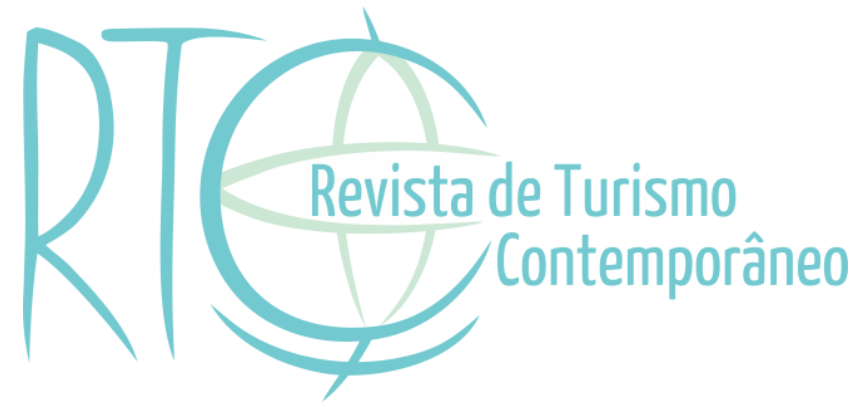

\title{
O turismo sustentável na percepção do viajante Gaúcho
}

\section{Sustainable tourism in a Gaucho's traveler perception}

\section{Natália Gomes da Silva}

Professora EAD, da Escola de Negócios da Universidade do Vale do Rio do Sinos -UNISINOS, São Leopoldo/RS, Brasil.

E-mail: nataliags@unisinos.br

Jefferson Marlon Monticelli

Doutorando em Administração pelo Centro Universitário La Salle Canoas-UNISINOS, São Leopoldo/RS, Brasil.

E-mail: jeffmarlon@hotmail.com 


\section{RESUMO}

Resumo: Sustentabilidade é um tema recorrente no século XX. No caso do setor de Turismo, também se mostra uma preocupação. Entretanto, verifica-se que não há um consenso sobre o conceito de turismo sustentável. As pesquisas realizadas sobre o tema restringem-se à dimensão dos fornecedores/prestadores de serviço, sendo que o tema foi pouco estudado na perspectiva do cliente/viajante. A partir desta contextualização, este trabalho tem como questões norteadoras: os potenciais clientes dos serviços de turismo consideram em suas decisões a questão da sustentabilidade ao planejarem suas viagens turísticas? Os potenciais clientes percebem a sustentabilidade como um diferencial das organizações que atuam no ramo de turismo? $\mathrm{O}$ objetivo desta pesquisa foi identificar hábitos relacionados ao comportamento do cliente de viagens a turismo, especialmente com enfoque no turismo sustentável. Foi realizada uma survey com 114 respondentes entre estudantes de Mestrado e servidores públicos do Judiciário Federal, em sua maioria, gaúchos. Por meio dos resultados, percebe-se que o Turismo Sustentável ainda não é visto de forma clara pelos viajantes e que nem sempre são consideradas atitudes de caráter sustentável quando do planejamento e realização de viagens a turismo.

Palavras-chave: Turismo sustentável. Sustentabilidade. Hábitos de consumo. Cliente.

\section{ABSTRACT}

Sustainability is a recurring topic in the twentieth century. For the tourism sector, there is not a concern about the concept of sustainable tourism. Research on the subject is limited to the suppliers/service providers dimension, since the topic has been little studied from the consumer/traveler perspective. From this context, this study has as guiding questions: Are the potential consumer of tourism services considering the issue of sustainability in their decisions when they plan their tourism travels? Do potential consumers perceive sustainability as a differential of those organizations working in the tourism industry? The objective of this study was to identify habits related to the tourism consumer behavior, especially focusing on sustainable tourism. A survey was conducted with 114 respondents between Master's students and civil servants of the Federal Judiciary. mostly, gaúchos. By the results, it is noticed that sustainable tourism is not clearly seen by travelers and that sustainable attitudes are not always considered when planning and conducting tourism travels.

Keywords: Sustainable tourism. Sustainability. Consumer habits. Consumer. 


\section{INTRODUÇÃO}

Os conceitos de sustentabilidade e desenvolvimento sustentável são de uso comum nos dias de hoje, embora sejam temas em discussão desde 1972, quando se reuniram representantes de 113 nações na Conferência de Estocolmo para discutir o meio ambiente (Körössy, 2008). Por um lado, é fato que, especialmente no século XXI, com as diferentes catástrofes climáticas (inundações, tsunamis, ciclones extratropicais, etc.), a questão ambiental ganhou destaque. Por outro lado, sustentabilidade tem se tornado uma variávelchave na competitividade por destinos turísticos, trazendo reconhecimento ao tema turismo sustentável (World Economic Forum, 2013).

A lógica do desenvolvimento sustentável permeia diferentes setores da economia: indústrias de diversos tipos, atividades de reflorestamento, extração mineral, produção de bens de consumo, enfim, uma variedade de ramos, desdobrando-se, inclusive, para o campo da Economia Solidária. No caso desta pesquisa, elegeu-se o setor de turismo, pois é considerado um dos que, contemporaneamente, tem papel central no desenvolvimento socioeconômico e na geração de empregos (Brasil, 2009b). Ainda, conforme a Fundação Instituto Brasileiro de Economia e Estatística (2010), as atividades relacionadas ao turismo geraram R\$168,8 bilhões em 2007, representando 7,1\% do setor de serviços e 3,6\% da economia brasileira, respondendo pela agregação de 3,6\% (R\$ 82,7 bilhões) de valor à economia. Dados da "Pesquisa anual de conjuntura econômica do turismo" (Brasil, 2011), mostram que, para 97\% das 80 maiores empresas de turismo no Brasil, houve crescimento de faturamento em 2010 e que havia perspectiva de ampliação do mercado de turismo para 2011, especialmente para as agências de viagens. Sob a perspectiva do cliente, conforme Tyrväinen et al. (2014), têm promovido o turismo sustentável e novos negócios nessa indústria.

Do ponto de vista de ações governamentais relacionadas ao turismo sustentável no Brasil, identificaram-se duas coordenadas pelo Ministério do Turismo: uma voltada aos fornecedores deste tipo de serviço (agências, estabelecimentos de hospedagem, empresas associadas, parceiros institucionais e de trade) e outra voltada aos usuários. A primeira delas é o prêmio Braztoa, destinado a reconhecer ações de sustentabilidade no setor (Fideles, 2015). Tem como critérios de reconhecimento das iniciativas o impacto ambiental do projeto, os benefícios socioculturais e econômicos, o incentivo ao turismo sustentável, a viabilidade 
financeira, a abrangência e a replicabilidade. Quanto aos viajantes, existe o programa Passaporte Verde, projeto do Ministério do Turismo, na forma de um portal web, que procura incentivar o turista a “(...) contribuir com o desenvolvimento sustentável local por meio de escolhas responsáveis durante o período de férias e lazer” (Brasil, 2015, não paginado). Dessa forma, percebe-se que há uma preocupação do Estado com a sustentabilidade das atividades turísticas e com o comportamento dos viajantes.

No campo acadêmico, existem diversas publicações sobre turismo sustentável, a maior parte delas abordando estudos de caso de locais que adotaram estratégias para tornarem-se destinos turísticos sustentáveis, isto é, na perspectiva de quem oferece o serviço e não de quem o utiliza. No entanto, na dimensão do cliente desses serviços e de seu comportamento, ainda há carência de estudos que associem o perfil do cliente que busca os destinos de turismo sustentável (Tyrväinen et al., 2014),

Como agravante, existe necessidade de clarificar o conceito de turismo sustentável, assim como desenvolver instrumentos práticos que possam mensurar a sustentabilidade nesse setor (Glyptou, Paravantis, Papatheodorou, \& Spilanis., 2014; Torres-Delgado \& Palomeque, 2014). Por conta disso, pergunta-se: os potenciais clientes dos serviços de turismo estão considerando em suas decisões a questão da sustentabilidade ao planejarem suas viagens turísticas? Os potenciais clientes percebem a sustentabilidade como um diferencial das organizações que atuam no ramo de turismo? A partir desses questionamentos, essa pesquisa teve por objetivo identificar hábitos relacionados ao comportamento do cliente de viagens a turismo, especialmente com enfoque no turismo sustentável. Para tanto, foi realizada uma survey por meio de um instrumento de pesquisa desenvolvido com suporte teórico. Trata-se de um tópico pouco explorado dentro do campo de estudo sobre turismo sustentável, carente de perspectivas críticas, inovadoras e que indiquem novas avenidas de pesquisa (Bramwell \& Lane, 2014). Além disso, é um setor econômico em expansão pelos dados já apresentados.

A estrutura desta pesquisa é composta, além desta seção, por uma breve apresentação de conceitos relevantes para este estudo, seguida do detalhamento dos aspectos metodológicos e da apresentação do perfil da amostra e dos resultados coletados. Finaliza-se com as conclusões mais relevantes sob o tema. 


\section{FUNDAMENTAÇÃO TEÓRICA}

De acordo com o exposto por Jansen (2003) a partir do Brundtland Report ${ }^{1}$ (1987), desenvolvimento sustentável é aquele que atende as necessidades das atuais gerações sem o comprometimento das gerações futuras. Em consequência, práticas sustentáveis são aquelas que se realizam minimizando ou neutralizando os impactos sociais, culturais e de meio ambiente. Esse conceito deriva de um raciocínio prático: sendo o planeta Terra uma fonte limitada de recursos nem sempre renováveis, caso o desenvolvimento econômico mundial mantenha a mesma marcha, não haverá recursos disponíveis para as gerações vindouras. Isso explica o porquê de, geralmente, associar-se sustentabilidade com práticas preservacionistas ou de cunho ecológico, embora as dimensões cultural e social também devam ser consideradas ao se pensar em desenvolvimento sustentável.

Como resgatado por Körössy (2008), as ideias primitivas de turismo sustentável remontam à década de 60 do século $\mathrm{XX}$, momento em que se começou a perceber que o turismo de massa poderia trazer consequências negativas, passando pela década de 70, com as preocupações iniciais da gestão dos visitantes e de fato consolidando-se como "turismo verde" na década de 80. Johnsen (2015) argumenta que a dificuldade em se estabelecer um consenso conceitual acerca do que seria turismo sustentável reporta-se ao fato de o turismo ser um campo multidisciplinar e ser uma área com problemas de imagem nos espaços acadêmicos, advinda das diferentes perspectivas que os trabalhos trazem. Glyptou et al. (2014), na mesma linha de Johnsen (2015), concluíram, em seus estudos, que a maior parte dos modelos sobre sustentabilidade é construída a partir de indicadores pouco agregados, o que mostra uma lacuna de um modelo universal que permita de fato analisar a sustentabilidade de um destino. Laven, Wall-Reinius, e Fredman. (2015), em seus trabalhos, resgatam diferentes autores, reforçando o conceito do Brundtland Report (1987), mas apontando que, nos dias de hoje, o turismo sustentável é visto como um equilíbrio entre o consumo, a transformação e a criação de recursos turísticos. Apontam ainda, que para alguns

\footnotetext{
${ }^{1}$ Brundtland, G. H. (1987) World Commission on Environment and Development. Our common future. Oxford: Oxford University Press.
} 
estudiosos do assunto, como Hardy et al. (2002 como citado em Laven et al., 2015), não se trata de um campo de estudos reconhecido totalmente, mas sim uma vertente reacionária em que se observa que os conceitos derivam das práticas dos atores que atuam no setor. Bramwell \& Lane (2014) reforçam esta impressão, apontando que as pesquisas sobre turismo sustentável surgiram, muitas vezes, como críticas às práticas tradicionalmente existentes, surgindo como opções alternativas ao status quo.

Para Bacal Melo, Widmer, e Pereira (2007, p. 179), “(...) turismo sustentável é aquele que, com base no planejamento e estruturação de suas práticas, considera a conservação ambiental, a autenticidade cultural e ainda a inclusão social, buscando sempre a qualidade dos serviços prestados, viabilizando a perenidade da atividade". Timur \& Getz (2009) acrescentam que, para a promoção do turismo sustentável, deve haver o envolvimento de três partes: o setor do turismo, a comunidade local do destino (poder público e outros grupos) e os defensores do meio ambiente. Essas partes nem sempre partilham dos mesmos interesses. Entretanto, Körössy (2008) relata que não há um consenso sobre o que é de fato turismo sustentável, principalmente devido ao conceito impreciso e complexo de aplicação da sustentabilidade (Torres-Delgado \& Palomeque, 2014).

Para Fratu (2011, p. 120), para se diagnosticar as necessidades de um turista, é necessário compreender três grupos de fatores:

(i) fatores pessoais: personalidade, autoimagem, atitudes, motivações, percepções, estilo de vida, idade, estilo de vida da família, profissão; (ii) fatores sociais: cultura, família, classe social, grupos de referência; e, (iii) fatores situacionais: tempo, ambiente físico, ambiente, ambiente social e o estado de espírito.

O autor utilizou essas categorias para realizar um estudo com turistas europeus. Devido ao contexto econômico de recessão, aqueles turistas passaram a optar por viagens mais curtas, com descontos e com maiores ofertas, estão dispostos a despender menos recursos financeiros para viajar. Esses fatores apareceram nas conclusões de Tyrväinen (2014). Na perspectiva do viajante, Tyrväinen (2014), por meio de uma pesquisa nos anos de 2009 a 2010, no norte da Finlândia identificaram que os frequentadores de resorts daquela localidade percebem a importância de se adotaram os princípios da sustentabilidade naqueles locais, porém, quando envolvia uma mudança de comportamento individual na escolha da hospedagem, na redução do consumo de recursos hídricos e de energia, ou em viajar em 
automóvel privado, mostravam-se menos engajados. Constataram também que a escolha do meio de hospedagem nem sempre era pautada pela busca de estabelecimentos eco-eficientes. Concluíram que a promoção de práticas sustentáveis no turismo não pode ficar sujeita exclusivamente ao comportamento dos viajantes, pois este é influenciado por fatores diversos.

Dos estudos apresentados, nota-se que não há um consenso sobre a pesquisa em Turismo Sustentável. Por outro lado, percebe-se que todos os trabalhos reportam ao nível de sustentabilidade das práticas adotadas pelos estabelecimentos turísticas. Do ponto de vista do clientes, os estudos elencados mostram que os viajantes têm preocupação quanto à sustentabilidade, mas ainda não a colocam em prática - não é uma escolha prioritária. Isso pode ser explicado porque as necessidades do consumidor de serviços turísticos podem ser afetadas por variáveis que envolvem questões mais individuais, como sociais e contextuais.

\section{ASPECTOS METODOLÓGICOS}

A partir das perspectivas apontadas na seção anterior, este estudo partiu de uma pesquisa exploratória, de corte transversal único, para compreender a influência da sustentabilidade na tomada de decisão de potenciais clientes do setor de turismo. Para a realização dessa pesquisa, por falta de consenso na literatura, foram utilizados os seguintes conceitos, baseados no "Guia de Viagens Ecológicas" (2009): (i) turismo sustentável: aquele que é realizado observando a responsabilidade ambiental (preservação do meio ambiente) e social (valorização da cultura e da sociedade local, promovendo o desenvolvimento); (ii) práticas de sustentabilidade: aquelas destinadas à preservação do meio ambiente, como construção ecológica, reaproveitamento de água, utilização de energia solar, etc. (iii) viagens a turismo: qualquer deslocamento de seu município realizado com fins de lazer, utilizando qualquer meio de transporte (aéreo, ferroviário, rodoviário, etc.), acompanhado ou sozinho. Excetuam-se as viagens a trabalho.

Esses entendimentos foram os alicerces para a construção do instrumento de coleta de dados, um questionário com 33 questões. As perguntas foram divididas em dois blocos: no primeiro (questões 1 a 9), mapeamento do perfil demográfico e genérico sobre hábitos de turismo, com uso de questões abertas e de múltipla escolha; o segundo bloco (questões 10 a 33) foi composto por sentenças, com uso de escala de Likert de 5 pontos, as quais procuraram identificar o nível de concordância/discordância dos respondentes quanto à maneira como 
usualmente comportam-se em relação ao planejamento da viagem, as rotinas no destino turístico, a eleição dos meios de transporte, a escolha do meio de hospedagem, os hábitos pessoais, o consumo na viagem e a percepção quanto aos impactos ambientais de sua viagem. A opção por mensuração com indicadores subjetivos foi definida com a finalidade de conceder maior aplicabilidade e comparação dos resultados em diferentes cenários.

O instrumento de coleta foi validado por uma estudante do Mestrado em Administração da Universidade do Vale do Rio dos Sinos [Unisinos]; dois estudantes do curso de Turismo da Pontifícia Universidade Católica do Rio Grande do Sul [PUC-RS]; por um gestor de agência turística; e por um pesquisador especialista na área de estatística aplicada da Unisinos. O instrumento de pesquisa também passou por uma fase de pré-teste junto a 10 respondentes, visando reduzir a possibilidade de erro no preenchimento dos questionários e na compreensão das orientações (Malhorta, 2009). Além disso, foram feitos testes de confiabilidade para as escalas, indicando a possível adequação do questionário. Após a visualização e teste realizado por parte deste grupo, foram realizadas algumas modificações nas questões existentes e acréscimo de outras, principalmente para captar melhor a dimensão de sustentabilidade na prestação de serviços na área de turismo.

Para essa pesquisa, a coleta de dados foi aplicada de maneira aleatória por meio de uma survey. Trabalhou-se com uma amostra da população selecionada pelo critério de conveniência, com pessoas do círculo social dos pesquisadores. O questionário final foi disponibilizado na internet por meio do sistema Google Docs, no primeiro semestre de 2012. O link para o formulário online foi publicado no Facebook na mesma data e encaminhado por e-mail para cerca de 90 pessoas, enfatizando que o público-alvo eram pessoas que viajam a turismo. Estimulou-se o efeito "bola de neve", solicitando que o link fosse divulgado entre indivíduos com o mesmo perfil. Destaca-se que as viagens a trabalho foram excluídas da pesquisa porque, na maioria dos casos, a eleição do destino, do meio de hospedagem e do meio de transporte guia-se por critérios econômicos e de utilidade da empresa ou do profissional, logo, mesmo que possam a vir a tornar-se uma oportunidade turística, não representam decisões dos viajantes. Por não se tratar de tema de amplo conhecimento e para evitar interpretações divergentes à que se propunha em cada questão, na parte introdutória do questionário foram apresentadas as três ideias básicas que deveriam ser observadas ao responder: turismo sustentável; práticas sustentáveis e viagens a turismo. Ademais, em alguns itens, foi colocado exemplo de situações relacionadas às sentenças e detalhamento de palavras-chave. 
Encerrado o prazo para resposta, houve coleta de 114 respostas obtidas, principalmente, entre estudantes de Mestrado e servidores públicos do Judiciário Federal A maior parte dos dados estava em condições de ser analisado porque não continha respostas em branco ou fora do formato solicitado. Apenas uma questão foi descartada da análise, a de número 8 , que perguntava sobre o conhecimento de determinados sites relacionados a turismo. Essa questão foi desconsiderada porque, quando da publicação do questionário, constava como de resposta obrigatória, sem trazer uma opção de "Nenhum". Nesse caso, os respondentes poderiam ter marcado qualquer resposta apenas para submeter o questionário. Tendo em vista que isso poderia prejudicar a fidedignidade dos dados, optou-se por não examinar essa questão. Além disso, foi utilizado como parâmetro até $10 \%$ de dados perdidos que foram substituídos pela média da questão correspondente (Malhorta, 2009).

\section{APRESENTAÇÃO E ANÁLISE DOS DADOS}

Quanto à análise de dados, ela envolve a partição, identificação e medida de variação em um conjunto de variáveis, seja entre elas mesmas ou entre uma variável dependente e uma ou mais variáveis independentes. Basicamente, há dois tipos de dados: (i) os qualitativos ou não métricos, que se referem aos atributos e categorias do objeto de estudo; e (ii) os quantitativos ou métricos, que implicam quantidade ou magnitude (Hair, 2009). Embora o Google Docs permita que se faça um resumo das respostas, inclusive com recurso de gráficos e percentuais, para o tratamento dos dados foi utilizado o software Statistical Package for Social Science [SPSS], versão 19.0, pois permite análises estatísticas mais depuradas. Depois de salvos em formato MS Excel (xls), os dados foram exportados para o SPSS, revisados e recodificados. Foram feitas algumas padronizações, especialmente nas questões em que havia campo aberto para responder (números 1, 2 e 9), de maneira a se aproveitar toda a amostra. Sendo assim, aplicou-se o software SPSS, versão 19.0, para tratamento dos dados quantitativos, priorizando-se a utilização de médias, frequência, desvio padrão, análise de variância (ANOVA), além da identificação de casos omissos, outliers e normalidade. Não foram detectados outliers. A verificação da assimetria e curtose indicou a normalidade dos dados.

Os resultados da análise dos dados são apresentados em quatro subseções diferentes: perfil da amostra; correlação entre variáveis; comparação entre grupos; e análise fatorial. A 
primeira subseção elucida as questões com variáveis discretas e categóricas. Na segunda e na quarta subseção, são trabalhadas as variáveis escalares, e na terceira terceira subseção, tanto variáveis categóricas quanto variáveis escalares.

Com relação às variáveis escalares, a que apresentou maior média foi a questão 20 (Sendo viável e seguro, opto por fazer caminhadas para conhecer os lugares que estou visitando), com 4,53 e desvio-padrão de 0,74. A de menor média foi encontrada na questão 29 (Mesmo quando viajo a turismo, prefiro fazer as refeições em redes de restaurantes e lanchonetes conhecidas em todo o mundo (Mc Donalds, por exemplo), com valor de 1,94 e desvio-padrão de 1,06.

\subsection{PERFIL DA AMOSTRA}

A Tabela 1 resume os dados relativos ao perfil da amostra, considerando estado de residência, estado civil, escolaridade e faixa etária dos 114 respondentes. Observa-se que a amostra pode ser considerada composta por gaúchos em sua maioria $(97,4 \%), 43,9 \%$ solteiros e 49,1\% casados ou em união estável (não houve viúvos respondentes), com alto nível de educação formal, já que 56,1\% são pós-graduados e 29,8\% têm nível superior. Quanto à faixa etária, a média foi de 33,89 anos, centrando-se na faixa de 32,29 a 35,49 anos para um intervalo de $95 \%$ de confiança. Percebe-se que o grupo é constituído principalmente por adultos jovens.

Em termos de quantidade de viagens a turismo realizadas no último ano, a média ficou de 3,11 viagens por respondente (intervalo entre 2,65 a 3,57 para 95\% de confiança), sendo que $70,2 \%$ da amostra realizou entre uma e 3 viagens.

Nos extremos, está um respondente que não realizou viagens $(0,9 \%)$ e outro que realizou $20(0,9 \%)$. Os demais respondentes (28\%) viajaram entre 4 e 12 vezes no último ano. Esses dados poderiam ser mais bem explorados em um segundo levantamento, procurando qualificar essas viagens: se são internacionais ou nacionais; qual o tempo de duração da viagem; se foram consideradas viagens dentro do próprio estado de residência etc. A complementação de informações poderia ser útil para ser cruzada com os dados estatísticos disponibilizados pelo IBGE e pelo Ministério do Turismo, até para compreender se esse grupo, de adultos jovens e com alta escolaridade, está sendo atingido pelas políticas de estímulo ao turismo. 
Tabela 1 - Residência, Estado Civil, Escolaridade e Distribuição Etária da Amostra

\begin{tabular}{lrc}
\hline Estado de Residência & Quantidade & Percentual \\
\hline RS & 111 & 97,4 \\
SC & 02 & 1,8 \\
PB & 01 & 0,9 \\
\hline Estado Civil & Quantidade & Percentual \\
\hline Solteiro(a) & 50 & 43,9 \\
Casado(a)/União Estável & 56 & 49,1
\end{tabular}

\begin{tabular}{|c|c|c|}
\hline Separado(a)/Divorciado(a) & 8 & 7 \\
\hline Escolaridade & Quantidade & Percentual \\
\hline Ensino Fundamental Incompleto ou & 04 & 3,5 \\
\hline Completo & & \\
\hline Ensino Médio Completo ${ }^{a}$ & 12 & 10,5 \\
\hline Ensino Superior Completo & 34 & 29,8 \\
\hline Pós-Graduação & 64 & 56,1 \\
\hline Faixa Etária & Quantidade & Percentual \\
\hline Menos que 20 anos & 02 & 1,76 \\
\hline Entre 20 e 29 anos & 37 & 32,46 \\
\hline Entre 30 e 39 anos & 50 & 43,86 \\
\hline Entre 40 e 49 anos & 16 & 14,03 \\
\hline Acima de 50 anos & 09 & 7,89 \\
\hline Total de respondentes & & 114 \\
\hline
\end{tabular}

Fonte: elaboração a partir dos dados coletados

a. No questionário, o respondente poderia optar por "Ensino Médio Incompleto ou Completo" ou "Ensino Superior". Como nenhum respondente escolheu "Ensino Médio Incompleto ou Completo" e 12 escolheram "Ensino Superior Incompleto", decidiu-se por apresentar esses dados como "Ensino Médio Completo", já que para se ingressar no Ensino Superior é necessário ter concluído o Ensino Médio, conforme legislação do Ministério da Educação e Cultura.

Quanto ao comportamento de compra, mais de dois terços dos respondentes (68,4\%) organiza a viagem por conta própria. A minoria utiliza apenas os serviços de agência de turismo (10,5\% da amostra) e 21,1\% adquirem parte de agências e parte por conta própria. Esse dado é interessante, especialmente se visto diante das expectativas favoráveis de ampliação do mercado para agências de turismo. De fato, pautando-se por essa amostra, há um número considerável de pessoas que não está utilizando os serviços de agências de turismo - isso pode ser um indicativo de que as agências precisam adotar providências para atingir esse público-alvo para de fato conseguirem a ampliação almejada.

Sobre viajar sozinho ou acompanhado, poucos viajam sós (3,5\% da amostra), a maior parte viaja com o cônjuge/namorado(a) $(44,7 \%)$ ou com familiares $(35,1 \%)$. A companhia dos amigos foi eleita por $16,7 \%$ da amostra. Do ponto de vista de mercado, isso representa para as agências de turismo, por exemplo, que ao adquirir seus serviços, possivelmente será para mais de um cliente (casal ou família). Os resultados encontrados na amostra guardam simetria com os levantados pelo Ministério do Turismo, na pesquisa “Hábitos de Consumo do Turismo 
Brasileiro" (Brasil, 2009), realizada entre junho e julho de 2009, com 2322 entrevistados, maiores de 18 anos e de todas as classes sociais. A Tabela 2 traz um apanhado dos dados dessa pesquisa, considerando o recorte de "clientes atuais" (cerca de 805 respondentes).

Comparando os dados da Tabela 2 com os dados da Tabela 1 e outros resultados apresentados nos parágrafos anteriores, verifica-se que tanto na pesquisa do Ministério do Turismo (Brasil, 2009) quanto na amostra estudada há predomínio de uma escolaridade elevada entre os viajantes (51,3\% com Ensino Superior ou mais no Ministério do Turismo e $85,9 \%$ na amostra deste estudo). Quanto à faixa etária, 86,8\% dos respondentes deste estudo estão entre 19 e 44 anos, enquanto 63,9\% na pesquisa brasileira, ou seja, a maior parte dos respondentes dos dois estudos é composta por adultos com até 44 anos.

Tabela 2 - Resumo dos resultados da pesquisa "Hábitos de Consumo do Turismo Brasileiro"

\begin{tabular}{|c|c|c|c|}
\hline & Categorias & Subcategorias & Percentual \\
\hline \multirow{4}{*}{\multicolumn{2}{|c|}{ Escolaridade }} & Ensino Fundamental & 12,3 \\
\hline & & Ensino Médio & 36,4 \\
\hline & & Ensino Superior ou & 51,3 \\
\hline & & \multicolumn{2}{|c|}{ mais } \\
\hline \multirow{3}{*}{\multicolumn{2}{|c|}{ Faixa etária $^{\mathrm{a}}$}} & 18 a 24 anos & 18,5 \\
\hline & & 25 a 34 anos & 25,2 \\
\hline & & 35 a 44 anos & 20,2 \\
\hline \multirow{5}{*}{\multicolumn{2}{|c|}{ Companhia de viagem $^{\mathrm{b}}$}} & Sozinho & 10,8 \\
\hline & & Amigos & 17 \\
\hline & & Cônjuge e filhos & 29,1 \\
\hline & & Cônjuge & 21,6 \\
\hline & & Outros Parentes & 15 \\
\hline \multirow{2}{*}{\multicolumn{2}{|c|}{$\begin{array}{l}\text { Hábito de organização da } \\
\text { viagem }\end{array}$}} & Conta própria & 79,5 \\
\hline & & Pacote de agência & 20,5 \\
\hline
\end{tabular}

Fonte: elaborado a partir de BRASIL (2009)

${ }^{\text {a }}$ Foram desconsiderados os percentuais para idades acima de 45 anos $(22,8 \%$ para respondentes entre 45 e 59 anos e $13,3 \%$ para respondentes com 60 anos ou mais), pois queria comparar-se apenas com o grupo mais característico da amostra pesquisada.

Ђ Foi desconsiderado o valor de 6,6\% relativo à categoria "Em grupo", não constante no presente estudo, o que prejudica a comparação.

No que tange aos companheiros de viagens, à exceção do percentual para "Amigos" que foi bastante semelhante $(16,7 \%$ desta pesquisa e $17 \%$ na pesquisa brasileira), os demais valores mostraram-se divergentes. De qualquer forma, pode-se perceber que tanto os respondentes deste estudo como os do estudo do ministério brasileiro preferem viajar acompanhados ou em grupo, sendo que uma minoria tem o hábito de viajar sozinha $(3,5 \%$ nesta pesquisa e 10,8\% no estudo brasileiro). Por último, comparado o hábito de organização de viagem, foi mostrado que a maior parte prefere organizar a viagem por conta própria

\footnotetext{
2 Os respondentes desta pesquisa foram divididos em três grupos: clientes atuais (pessoas que viajaram nos últimos dois anos), potenciais clientes (que não viajaram nos últimos dois anos mas pretendem viajar nos próximos dois anos) e não clientes (não viajaram e nem pretendem viajar).
} 
(68,4\% desta amostra e 79,5\% da amostra brasileira) a comprar pacote de uma agência $\left(10,5 \%\right.$ neste estudo e $20,5 \%$ do outro). ${ }^{3}$ Em linhas gerais, os resultados identificados no presente estudo não destoam muito daqueles verificados em âmbito brasileiro, em pesquisa de maior alcance e heterogeneidade de participantes. Evidências disso são o predomínio de alta escolaridade, hábitos de viajar acompanhado e de organização de viagem, assim como faixa etária dos respondentes.

Encerrando o perfil da amostra, quando questionados sobre qual destino escolheriam para viajar, caso ganhassem um pacote de viagem, os locais com maior frequência foram Paris (França) e a Europa como um todo, ambos com 9,6\% cada, seguidos por Nova Iorque (Estados Unidos), com 6,1\% das respostas, e Londres (Inglaterra), com 5,3\%. Destinos brasileiros foram escolhidos por 6 respondentes $(5,3 \%)$, sendo que Fernando de Noronha ficou com 3,5\% do total de respostas. Quatro respondentes escolheram mais de um destino, logo, foram desconsiderados. Como os institutos e órgãos públicos que fazem pesquisas sobre turismo costumam categorizar os destinos por continente, foi realizado novo agrupamento utilizando esse critério e comparando com os dados da Organização Mundial do Turismo [OMT], disponibilizados pelo Ministério do Turismo Brasileiro (BRASIL, 2009b), referentes ao ano de 2008. Os resultados estão na Tabela 3.

Tabela 3 - Frequência de destino agrupado por continente

\begin{tabular}{crlr}
\hline Continente de destino & Quantidade & Percentual & Percentual OMT \\
\hline África & 03 & 2,72 & 5,09 \\
América do Norte & 17 & 15,45 & 10,61 \\
América Central e do Sul & 16 & 14,54 & 5,36 \\
Ásia & 10 & 9,1 & 26 \\
Europa & 54 & 49,09 & 52,94 \\
Oceania e arquipélagos & 10 & 9,1 & 0 \\
\hline Total & $\mathbf{1 1 0}$ & $\mathbf{1 0 0}$ & \\
\hline Fonte: elaboração a partir dos dados coletados e de Brasil (2009b).
\end{tabular}

${ }^{\text {a }}$. Foram somados os valores de 3,10\% (América Central e Caribe) e 2,26\% (América do Sul)

b. Os valores foram considerados em conjunto com a Ásia naquela pesquisa.

Pode-se constatar que, assim como os turistas mundiais, o maior interesse como destino de viagem para os brasileiros é a Europa, com 49,09\% das respostas frente aos 52,94\% registrados em âmbito mundial. Os demais índices não aparentam semelhanças, à exceção do continente africano, que foi o com menor valor para os dois grupos $(2,72 \%$ dos brasileiros e 5,09\% para os turistas do mundo). Como povo latino-americano, percebe-se um interesse maior pelos lugares da América do Sul e Central (14,54\%) que por parte dos turistas

\footnotetext{
${ }^{3}$ Esses valores não totalizam $100 \%$ porque na atual pesquisa existia uma terceira categoria: em parte por conta e em parte por agência.
} 
do mundo inteiro (5,36\%). Ainda, mesmo considerando a Ásia e Oceania em conjunto, os percentuais mostram menor interesse $(18,2 \%)$ para os brasileiros frente $26 \%$ dos turistas do mundo. Ressalva-se que essa não é uma comparação linear prefeita, já que se trata de dados de 2012 (este estudo) e de 2008 (OMT), e que as decisões sobre viagem são constantemente influenciadas por oscilações nos fatores econômicos (câmbio, crises financeiras), socioculturais (festividades e eventos, como Copa do Mundo, Olimpíadas) e outros (vulcões, nevascas, tsunamis, doenças como a gripe aviária), os quais em um intervalo de quatro anos podem mostrar variação.

\subsection{CORRELAÇÃO ENTRE VARIÁVEIS}

Após investigar as questões que envolviam variáveis categóricas e discretas do instrumento de pesquisa, dá-se prosseguimento à análise com as estatísticas relativas às variáveis escalares (questões 10 a 33). O primeiro exame realizado foi o de verificação de correlação entre variáveis, utilizando como referência o coeficiente de Correlação de Pearson $(r)$. Para esta análise, foram consideradas que estavam associadas as variáveis que tivessem $p$ $\leq 0,05$ ou $p \leq 0,01$, já que, com esses valores, assume-se que a probabilidade da hipótese nula (inexistência de relação) ser aceita em decorrência de erro amostral é significativamente baixa. Ainda, seguindo Malhorta (2009), para estabelecer a intensidade da relação, definiu-se: relação nula: $r=0$; relação fraca: $0,1 \leq r \leq 0,3$; relação moderada: $0,4 \leq r \leq 0,6$; relação forte: $0,7 \leq r \leq 0,9$; relação perfeita: $r=1$.

A Tabela 4 apresenta os coeficientes de Correlação de Pearson (valores na parte superior da célula), bem como o nível de significância (valores inferiores) para as variáveis de 10 a 33. As correlações fracas foram sinalizadas na cor amarela, enquanto as moderadas na cor verde, para facilitar a visualização. Pode-se verificar, ao observar a Tabela 4, que todas as questões apresentam algum grau de correlação entre si, que pode variar de três correlações (questões 11, 13 e 17) a 15 correlações (questões 21 e 28). Houve 15 correlações moderadas; as demais, fracas. A grande maioria das correlações apresenta relação direta entre as variáveis (aumentando o valor na escala de uma, aumentará o da outra) e, apenas seis mostraram relação inversa (se uma variável aumenta, a outra diminui). 
Tabela 4 - Correlação Entre as Variáveis das Questões 10 a 33
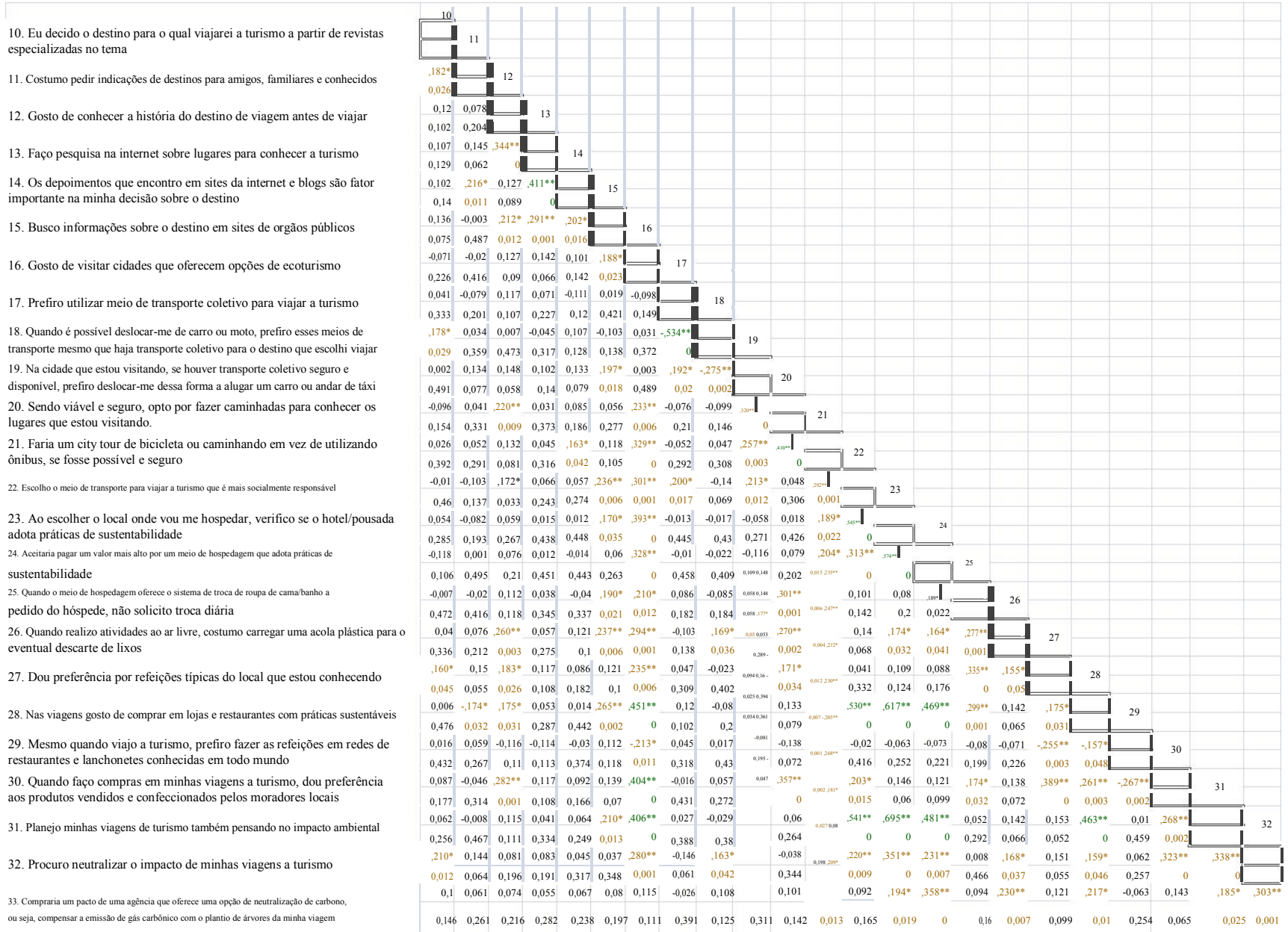

* Correlação é significante para $\mathrm{p}<0,05$ (unicaudal). ** Correlação é significante para $\mathrm{p}<0,01$ (unicaudal). Fonte: elaboração a partir dos dados coletados.

As questões 16 (Gosto de visitar cidades que oferecem opções de ecoturismo), 21 (Faria um city tour de bicicleta ou caminhando em vez de utilizando ônibus, se fosse possível e seguro) e 28 (Nas viagens gosto de comprar em lojas e restaurantes com práticas sustentáveis) são as que apresentaram correlação com maior número de outras questões (14 e 15 questões, respectivamente). Pode-se conjecturar que, no caso da questão 16, geralmente pessoas que apreciam viagens para destinos que oferecem opções de ecoturismo podem ter hábitos associados à preservação do meio ambiente e à sustentabilidade, o que guardaria coerência com as demais questões com a qual possui correlação. Quanto às questões 21 e 28, não se visualizam hipóteses deduzidas apenas a partir dos resultados encontrados, necessitando de investigações adicionais.

O nível de correlação mais alto foi encontrado entre a questão 23 (Ao escolher o local onde vou me hospedar, verifico se o hotel/pousada adota práticas de sustentabilidade) e 
questão 31 (Planejo minhas viagens de turismo também pensando no impacto ambiental), com $r=0,695$ para $p$ aproximando-se de zero e 48\% de variância compartilhada entre elas, isto é, relação moderada, quase forte, e direta. Este resultado aparenta ser empiricamente viável, pois, se alguém planeja uma viagem pensando em seu impacto ambiental, certamente poderá optar por um meio de hospedagem que tenha visão de sustentabilidade e adote práticas para reduzir o impacto de suas atividades. Por sinal, a questão 31 foi a que apresentou a maior índice de correlação moderado (com as questões 16, 22, 23, 24 e 28).

A relação mais alta e inversa foi verificada entre a questão 17 (Prefiro utilizar meio de transporte coletivo - avião, trem, ônibus- para viajar a turismo.) e a questão 18 (Quando é possivel deslocar-me de carro ou moto, prefiro esses meios de transporte mesmo que haja transporte coletivo para o destino que escolhi para viajar), com $r=-0,534$, para $p$ aproximando-se de zero. Essa correlação também faz sentido na prática, já que, caso um viajante prefira transporte coletivo, é provável que ele evite meios de transporte individuais e vice-versa. Não foi identificada correlação entre estar ou não acompanhado na viagem e a utilização de meio de transporte individual ou coletivo. Especificamente quanto ao meio de transporte, outros critérios são utilizados na escolha, como o tempo disponível para viajar, o conforto, a viabilidade do meio escolhido, enfim, atributos que fugiram ao alcance desta pesquisa, mas que podem ser explorados em pesquisas posteriores, inclusive de caráter mais qualitativo. Como a análise de correlação foi feita desvinculada de quaisquer demais hipóteses, não é possível assumir-se outras conclusões, sem correr o risco de se postular algo apenas com base no senso comum.

\subsection{COMPARAÇÃO ENTRE GRUPOS}

O próximo teste estatístico aplicado à base de dados foi a Análise de Variância [ANOVA]. As variáveis categóricas passíveis da aplicação deste teste eram as das questões 3 (estado civil, com três possibilidades de resposta), quatro (escolaridade, com quatro possibilidades de respostas), seis (companhia nas viagens, com quatro possibilidades de resposta) e sete (como é feita a aquisição da viagem, com três possibilidades de respostas). De pronto já se verifica a inviabilidade de aplicação do Teste $t$ de Student, pois sempre seriam mais de três grupos para comparação e esse teste só pode ser utilizado para dois grupos. 
Aplicada a ANOVA, tendo como fator as questões categóricas e como variáveis dependentes as questões escalares (dez a 33), foram encontrados indícios de que existiam diferenças entre as médias dos grupos para sete situações, observando-se o $p$ valor da ANOVA para $\mathrm{F}$ (considerado significativo $p \leq 0,05$ ) conforme mostra a Tabela 5 .

Tabela 5 - Variáveis que apresentaram $p$ valor significativo para $\mathrm{F}$

\begin{tabular}{|c|c|c|c|}
\hline Fator & Variável dependente (sentenças) $^{\mathrm{a}}$ & Significância ( $p$ valor) & Valor de F \\
\hline \multirow{3}{*}{ Estado civil } & 19 - transporte coletivo X táxi, carro & 0,019 & 4,136 \\
\hline & $33-$ aquisição de pacotes de agência que & 0,012 & 4,582 \\
\hline & neutralizam o carbono & & \\
\hline \multirow{2}{*}{ Escolaridade } & 12 - história do destino de viagem & 0,036 & 2,952 \\
\hline & 26 - sacola plástica para descarte de lixo & 0,022 & 3,356 \\
\hline \multirow{2}{*}{$\begin{array}{ll}\begin{array}{l}\text { Forma } \\
\text { compra }\end{array} & \text { de }\end{array}$} & 29 - refeições em redes de restaurantes & 0,021 & 3,982 \\
\hline & mundiais & & \\
\hline \multirow{2}{*}{$\begin{array}{l}\text { Companhia } \\
\text { na viagem }\end{array}$} & 18 - preferência por carro e moto & 0,04 & 2,86 \\
\hline & 21 - city tour de bicicleta ou caminhando & 0,05 & 2,62 \\
\hline & $* p \leq 0,05$ & tir dos dados. & \\
\hline
\end{tabular}

Após essa primeira triagem, foram verificados os valores para as comparações múltiplas a partir do parâmetro Scheffe. Os resultados significativos $(p \leq 0,05)$ foram encontrados apenas nos fatores "Estado Civil" e "Forma de Compra", nos grupos apresentados na Tabela 6 .

Tabela 6 - Grupamentos que apresentaram $p$ valor significativo

\begin{tabular}{|c|c|c|c|}
\hline Fator & Variável dependente (questão) & Grupos & $\begin{array}{l}\text { Significância } \\
(p \text { valor })\end{array}$ \\
\hline \multirow{2}{*}{ Estado civil } & $\begin{array}{l}19 \text { - transporte coletivo ou utilização táxi, } \\
\text { carro para deslocar-se no destino }\end{array}$ & Separado(a) X Solteiros & 0,027 \\
\hline & $\begin{array}{l}33 \text { - aquisição de pacotes de agência que } \\
\text { neutralizam o carbono }\end{array}$ & $\begin{array}{l}\text { Casado(a)/União estável } \mathrm{X} \\
\text { Separado(a) }\end{array}$ & 0,047 \\
\hline $\begin{array}{l}\text { Forma } \\
\text { compra }\end{array}$ & $\begin{array}{l}29-\text { refeições em redes de restaurantes } \\
\text { mundiais }\end{array}$ & $\begin{array}{l}\text { Adquire de agências } \mathrm{X} \\
\text { Organiza por conta }\end{array}$ & 0,043 \\
\hline
\end{tabular}

Fonte: elaborado a partir dos dados.

Nos demais fatores, $p$ valor foi superior a 0,05 , indicando não haver diferenças significativas entre as médias dos grupos. A partir dos resultados, como a maioria dos grupos dentro dos fatores não apresentou valores significativos para as diferenças entre as médias, realizada a comparação dos grupos pela ANOVA, pode-se concluir que, para esta amostra, há certa homogeneidade entre as médias dos diferentes grupos, não sendo identificadas diferenças significativas. 


\subsection{ANÁLISE FATORIAL}

O último teste estatístico ao qual foi submetida a base de dados foi a Análise Fatorial Exploratória [AFE], com o objetivo de identificar os fatores subjacentes e também depurar o questionário, especialmente porque este instrumento de pesquisa não seguiu nenhum modelo pré-existente. É considerado um Fator o conjunto de variáveis que possuem alta correlação entre si e baixa com as demais. A Tabela 7 procura compilar os resultados obtidos por meio da AFE, método de rotação Varimax. Destaca-se que foram encontrados oito fatores, os quais explicam 64,16\% da variância, com $\mathrm{KMO}=0,702$ e teste de especificidade de Bartlett com significância tendendo a zero. As variáveis que apareceram em mais de um fator foram alocadas naquele em que respondiam pela maior carga compartilhada.

Quando construído o instrumento de coleta, havia certa expectativa de relações entre algumas variáveis. Isso ficou comprovado na maior parte dos casos. Entende-se que há desvio do inicialmente previsto com relação aos Fatores 5 e 7, pois imaginava-se que a variável da questão 15 fosse mais coerente com o conjunto de valores do Fator 4; que a variável da questão 32 estaria mais propensa de ser alocada ou no Fator 1 ou no Fator 8; e que a variável da questão 11 também estaria mais associada ao Fator 4.

Algumas variáveis que ficaram agrupadas no mesmo fator apresentam indicação de carga compartilhada negativa. Isso é explicado pelo fato de, embora estejam no mesmo agrupamento, uma resposta torna a outra excludente, pois, ao se adotar determinada conduta (opção por transporte coletivo, por exemplo), é possível que se deixe de adotar a outra concorrente (transporte de moto ou carro, no mesmo exemplo). 
Tabela 7 - Fatores, variáveis e cargas compartilhadas

\begin{tabular}{|c|c|c|c|}
\hline Fatores & Denominação & Variáveis Isoladas & Carga compartilhada \\
\hline \multirow{5}{*}{ FATOR 1} & \multirow{5}{*}{ Apreço ambiental } & 23. Ao escolher o local onde vou me hospedar, verifico se o hotel/pousada adota práticas de sustentabilidade. & 0,855 \\
\hline & & 31. Planejo minhas viagens de turismo também pensando no impacto ambiental. & 0,816 \\
\hline & & $\begin{array}{l}\text { 22. Escolho o meio de transporte para viajar a turismo que é mais socialmente responsável (menor impacto ao } \\
\text { meio ambiente). }\end{array}$ & 0,775 \\
\hline & & 28. Nas viagens gosto de comprar em lojas e restaurantes com práticas sustentáveis & 0,713 \\
\hline & & 16. Gosto de visitar cidades que oferecem opções de ecoturismo (cavalgadas, mergulho, trilhas etc.) & 0,529 \\
\hline \multirow{3}{*}{ FATOR 2} & \multirow{3}{*}{$\begin{array}{l}\text { Responsabilidade } \\
\text { social }\end{array}$} & $\begin{array}{l}\text { 29. Mesmo quando viajo a turismo, prefiro fazer as refeições em redes de restaurantes e lanchonetes conhecidas } \\
\text { em todo o mundo (Mc Donalds, por exemplo). }\end{array}$ & $-0,733$ \\
\hline & & $\begin{array}{l}\text { 30. Quando faço compras em minhas viagens a turismo, dou preferência aos produtos vendidos e } \\
\text { confeccionados pelos moradores locais. }\end{array}$ & 0,691 \\
\hline & & 27. Dou preferência por refeições típicas do local que estou conhecendo. & 0,546 \\
\hline \multirow[b]{2}{*}{ FATOR 3} & \multirow[b]{2}{*}{$\begin{array}{l}\text { Transporte para } \\
\text { deslocamento }\end{array}$} & 17. Prefiro utilizar meio de transporte coletivo (avião, trem, ônibus) para viajar a turismo. & $-0,844$ \\
\hline & & $\begin{array}{l}\text { 18. Quando é possível deslocar-me de carro ou moto, prefiro esses meios de transporte mesmo que haja } \\
\text { transporte coletivo para o destino que escolhi para viajar. }\end{array}$ & 0,801 \\
\hline \multirow{3}{*}{ FATOR 4} & \multirow{3}{*}{$\begin{array}{l}\text { Informações } \\
\text { sobre o destino }\end{array}$} & 13. Faço pesquisa na internet sobre lugares para conhecer a turismo. & 0,846 \\
\hline & & $\begin{array}{l}\text { 14. Os depoimentos que encontro em sites da internet e blogs são fator importante na minha decisão sobre o } \\
\text { destino. }\end{array}$ & 0,710 \\
\hline & & 12. Gosto de conhecer a história do destino de viagem antes de viajar. & 0,474 \\
\hline \multirow{3}{*}{ FATOR 5} & \multirow{3}{*}{ Condutas pessoais } & $\begin{array}{l}\text { 25. Quando o meio de hospedagem oferece o sistema de troca de roupa de cama/banho a pedido do hóspede, } \\
\text { não solicito troca diária. }\end{array}$ & 0,701 \\
\hline & & $\begin{array}{l}\text { 26. Quando realizo atividades ao ar livre (caminhadas, trilhas ecológicas), costumo carregar uma sacola plástica } \\
\text { para o descarte de eventuais lixos. }\end{array}$ & 0,591 \\
\hline & & $\begin{array}{l}\text { 15. Busco informações sobre o destino em sites de órgãos públicos (Prefeituras, Governo do Estado, Secretarias } \\
\text { de Turismo, sites oficiais). }\end{array}$ & 0,512 \\
\hline \multirow{3}{*}{ FATOR 6} & \multirow{3}{*}{$\begin{array}{l}\text { Transporte no } \\
\text { local }\end{array}$} & $\begin{array}{l}\text { 19. Na cidade em que estou visitando, se houver transporte coletivo (metrô, ônibus, etc.) seguro e disponível, } \\
\text { prefiro deslocar-me dessa forma a alugar um carro ou andar de táxi. }\end{array}$ & 0,729 \\
\hline & & 1. Faria um city tour de bicicleta ou caminhando em vez de utilizando ônibus, se fosse possível e seguro. & 0,600 \\
\hline & & 20. Sendo viável e seguro, opto por fazer caminhadas para conhecer os lugares que estou visitando. & 0,590 \\
\hline \multirow[b]{2}{*}{ FATOR 7} & \multirow[b]{2}{*}{$\begin{array}{l}\text { Planejamento } \\
\text { neutralização }\end{array}$} & 10. Eu decido o destino para o qual viajarei a turismo a partir de revistas especializadas no tema. & 0,766 \\
\hline & & $\begin{array}{l}\text { P2. Procuro neutralizar o impacto de minhas viagens a turismo (economizo água, luz, utilizo produtos } \\
\text { biodegradáveis etc.). }\end{array}$ & 0,538 \\
\hline
\end{tabular}

Revista de Turismo Contemporâneo-RTC, Natal, v. 4, n.2, p.262-285, jul./dez. 2016. 


\begin{tabular}{|c|l|l|c|}
\hline & & 11. Costumo pedir indicações de destinos para amigos, familiares e conhecidos. & \\
\hline \multirow{2}{*}{ FATOR 8} & Custo ambiental & $\begin{array}{l}\text { 33. Compraria um pacote de uma agencia que oferece opção de neutralização do carbono, ou seja, compensar a } \\
\text { emissão de gás carbônico com o plantio de árvores da minha viagem. }\end{array}$ & 0,735 \\
\cline { 2 - 5 } & 24. Aceitaria pagar um valor mais alto por um meio de hospedagem que adota práticas de sustentabilidade. & 0,601 \\
\hline
\end{tabular}

$* \mathrm{KMO}=0,702 * *$ Significância teste de especificidade de Bartlett $\approx 0,00$. Fonte: elaborado a partir dos dados estatísticos. 


\section{CONSIDERAÇÕES FINAIS}

Essa pesquisa teve o objetivo de identificar alguns hábitos relacionados ao comportamento do cliente de viagens a turismo, com enfoque no turismo sustentável, procurando responder a duas questões, principalmente: os potenciais clientes dos serviços de turismo estão considerando em suas decisões a questão da sustentabilidade ao planejarem suas viagens turísticas? Os potenciais clientes percebem a sustentabilidade como um diferencial das organizações que atuam no ramo de turismo?

A amostra de respondentes foi composta majoritariamente por gaúchos (em torno de 97\%), jovens adultos (entre 20 a 35 anos), com alto nível de escolaridade formal (maior parte com ensino superior e pós-graduação), que viajaram entre uma a três vezes no último ano, preferem viajar acompanhados a viajar sozinhos e optam por organizar a viagem por conta própria a comprar de agências de turismo. Embora se tivesse percebido viés na amostra, pela maneira como o questionário foi divulgado (entre estudantes de Mestrado e servidores públicos do Judiciário Federal, principalmente), alguns dados encontraram semelhança com pesquisa feita pelo Ministério do Turismo em todo o Brasil, entre eles a escolaridade, e as preferências por viajar acompanhados e estruturar a viagem por conta.

Se ganhassem um pacote de viagem, a maioria dos respondentes deslocar-se-ia para a Europa e grandes cidades mundiais (Paris, Nova Iorque e Inglaterra), isto é, para destinos tradicionais, o que é próximo ao que foi respondido por viajantes em 2008. Uma diferença encontrada foi o maior interesse em viajar pela América Central e do Sul com relação à amostra mundial, o que talvez possa ser explicado tanto pela facilidade do idioma quanto pelas opções de realizar as viagens de carro e outros transportes menos onerosos que avião. No entanto, reforça-se que como a análise de correlação foi feita desvinculada de quaisquer demais hipóteses, não é possível assumir-se outras conclusões de maneira peremptória.

Da aplicação dos testes para verificação de correlações (Correlação de Pearson) e de comparação entre grupos (Análise de Variância - ANOVA), verificou-se, no primeiro caso, que diversas variáveis estavam correlacionadas, com relações fracas e moderadas, na sua maioria direta, tendo níveis de significância para o $p$ valor de $<0,05$ ou $<0,01$. Quanto às diferenças entre as médias de grupos (entre grupos), constataram-se apenas três casos, o que 
levou a concluir que há uma certa homogeneidade entre as respostas dos diferentes grupos, ao menos para a amostra pesquisada e assumindo um $p$ valor $<0,05$.

Por meio do último teste, Análise Fatorial Exploratória (AFE), foram mapeados oito fatores, que explicam $64,16 \%$ da variância, com $\mathrm{KMO}=0,702$ e teste de especificidade de Bartlett com significância tendendo a zero. A AFE permitiu dividiu os fatores: Apreço ambiental; Responsabilidade social; Transporte para deslocamento; Informações sobre o destino; Condutas pessoais; Transporte no local; Planejamento e neutralização; Custo ambiental. Considerando os propósitos delineados por meio do instrumento de pesquisa, infere-se que a AFE apresentou resultados, em sua maioria, semelhantes aos esperados.

Por fim, em uma reflexão sobre os resultados e resgatando as indagações iniciais deste estudo, percebe-se que o Turismo Sustentável ainda não é visto de forma clara pelos viajantes e que nem sempre são consideradas atitudes de caráter sustentável quando do planejamento e realização de viagens a turismo. Isto pode ser ilustrado pela resposta à questão 31 - Planejo minhas viagens de turismo também pensando no impacto ambiental - cuja média das respostas ficou em 2,18, ou seja, mais próximo do valor inferior da escala (Discordância), com 1,06 de desvio-padrão. Esses resultados mostram que ainda se trata de um campo para investigações mais acuradas, verificando que outros fatores os viajantes consideram ao planejar uma viagem. De acordo com os resultados auferidos, as práticas de sustentabilidade ainda são pouco valorizadas, representando também uma oportunidade de formulação de políticas públicas e de iniciativas das instituições e empresas que atuam no mercado do Turismo para conscientizar a população e assim, agregar valor ao seu negócio e promover, efetivamente, a sustentabilidade.

\section{REFERÊNCIAS}

Bacal, S. S., Melo, A. J. S. De, Widmer, G. M., \& Pereira, R. S. (2007) Turismo sustentável no Brasil: utopia ou possibilidade? Revista Gerenciais, São Paulo, 6(2), 175-181.

Brundtland, G. H. (1987) World Commission on Environment and Development. Our common future. Oxford: Oxford University Press

Bramwell, B., \& Lane, B. (2014). The "critical turn" and its implications for sustainable tourism research. Journal of Sustainable Tourism, 22(1), 1-8.

Brasil. (2009) Ministério do Turismo. Hábitos de consumo do turismo do brasileiro. Brasília: Ministério do Turismo. Disponível em: <http://www.turismo.gov.br/turismo/o_ministerio/ publicacoes/cadernos_publicacoes/02pesquisa_habitos.html $>$. Acesso em 24 jan. 2012. 
Brasil (2009b) Ministério do Turismo. Panorama do turismo no mundial. Brasília: Ministério do Turismo. Disponível em: <http://www.dadosefatos.turismo.gov.br/ export/sites/default/dadosefatos/estatisticas_indicadores/downloads_estatisticas/Estatxstica_e _Indicadores_de_turismo_no_Mundo_-_2009_1_3_.pdf $>$. Acesso em 28 ago. 2015.

Brasil. (2011). Ministério do Turismo. Pesquisa anual de conjuntura econômica do turismo. EBAPE/Núcleo de Turismo. Rio de Janeiro: Fundação Getúlio Vargas, 7. ed. 68 p. Disponível em: <http://www.dadosefatos.turismo.gov.br/export/sites/default/dadosefatos /conjuntura_economica/pesquisa_conjuntura_turismo/downloads_pesquisa_conjuntura_turis mo/pacet_10_03.pdf $>$ Acesso em: 25 jan. $20 \overline{1} 2$

Brasil.(2015). Ministério do Turismo. Passaporte Verde. Recuperado em 10 de agosto, 2015 de http://www.passaporteverde.org.br/campanha/sobre

Fideles, P. (2015). Estão abertas as inscrições para o Prêmio Braztoa. Ministério do Turismo. 21 ago. 2015. Recuperado em 28 de agosto, 2015, de http://www.turismo.gov.br/programas/5398-pr\%C3\%AAmio-bratzoa.html

Fundação Instituto Brasileiro de Geografia e Estatística [IBGE]. (2010). Economia do Turismo: uma perspectiva macroeconômica 2003-2007. Rio de Janeiro: IBGE. Recuperado em 24 de janeiro, 2012, de http://www.dadosefatos.turismo.gov.br/export/sites/default/dadosefatos/outros estudos/estudos_ibge/downloads_estudos_pesquisas_IBGE/Economia_do_Turismo_Uma_per spectiva_macroeconxmica_-_2003-2007_IBGE.pdf.

Fratu, D. (2011). Factors of influence and changes in the tourism consumer behaviour. Bulletin of the Transilvania University of Braşov, 4(1), 119-126.

Glyptou, K., Paravantis, J. A., Papatheodorou, A., \& Spilanis, A. (2014). Tourism Sustainability Methodologies: A Critical Assessment. IISA, The International Conference on Information, Intelligence, Systems and Applications, 182-187, 5th

Guia de viagens ecológicas: lugares incríveis, experiências verdes. (2009) (A., Medina \& E., Rocha. Trad.). Publifolha, p. 6-17.

Hair, Jr., J. F. et. al. (2009) Análise multivariada de dados. (6a Ed.) Porto Alegre: Bookman.

Jansen, L. (2003). The challenge of sustainable development. Journal of Cleaner Production $11,231-245$.

Johnsen, C. (2015). Sun, Sand, Sea \& Sustainability? A Study on Sustainable Tourism and Mass Tourism Management for the Islands of the Bahamas. Suécia: Department of Sociology, Lund University.

Körössy, N. (2008). Do turismo predatório ao turismo sustentável: uma revisão sobre a origem e a consolidação do discurso da sustentabilidade na atividade turística. Caderno Virtual de Turismo, 8(2), 56-68. 
Laven, D.N., Wall-Reinius, S., \& Fredman, P. (2015). New Challenges for Managing Sustainable Tourism in Protected Areas: An Exploratory Study of the European Landscape Convention in Sweden. Society \& Natural Resources: An International Journal, 1-18.

Malhotra, N. K. (2009) Pesquisa de marketing: uma orientação aplicada. (5a Ed.) Porto Alegre: Bookman.

Organização Mundial do Turismo [OMT] (2009). World Tourism Barometer. Madrid.

Tarrant, M. A., Lyons, K., Stoner, L., Kyle, G. T., Wearing, S., \& Poudyal, N. (2014). Global citizenry, educational travel and sustainable tourism: evidence from Australia and New Zealand. Journal of Sustainable Tourism, 22 (3), 403-420.

Timur, S., \& Getz, D. (2009). Sustainable tourism development: how do destination stakeholders perceive sustainable urban tourism? Sustainable Development, 17, 220-232.

Torres-Delgado, A., \& López Palomeque, F. (2014). Measuring sustainable tourism at the municipal level. Annals of Tourism Research, 49, 122-137.

World Economic Forum. (2013) The Global Competitiveness Report 2013-2014: Full Data

Edition. $\quad$ Recuperado em 18 de janeiro 2012 de
http://www3.weforum.org/docs/WEF_GlobalCompetitivenessReport_2013-14.pdf 